\title{
Safety Status of Schools in Shiraz and its Related Factors
}

\author{
Soheila Shaghaghian, ${ }^{1,2,}$ Belgheys Malekzadeh, ${ }^{3}$ and Mehrab Sayadi ${ }^{4}$ \\ ${ }^{1}$ Social Determinants of Health Research Center, Vice Chancellor for Health, Shiraz University of Medical Sciences, Shiraz, IR Iran \\ ${ }^{2}$ Non-communicable Diseases Research Center, Shiraz University of Medical Sciences, Shiraz, Iran \\ ${ }^{3}$ Adolescent, Youth, and School Health in I.R. Iran, Vice Chancellor for Health, Shiraz University of Medical Sciences, Shiraz, IR Iran \\ ${ }^{4}$ Biostatistics Department, Medical School, Shiraz University of Medical Sciences, Shiraz, IR Iran \\ "Corresponding author: Soheila Shaghaghian, Health System Research Office, Shiraz University of Medical Sciences, Shiraz, IR Iran. Tel: +98-9177159550, Fax: +98-7132122495, \\ E-mail: shaghaghia@sums.ac.ir
}

Received 2016 July 13; Revised 2016 August 06; Accepted 2016 August 08.

\begin{abstract}
Objectives: Due to the high impact of school safety on students' health, this study was conducted to determine safety status of the schools of Shiraz and its related factors.

Methods: In this cross-sectional study, 310 schools of Shiraz during year 2013 were selected by randomized multi-stage sampling. Our data-gathering tool was a valid and reliable researcher-made questionnaire which was designed based on the school health guideline standardized by Institute of standards and industrial research of Iran. Using this questionnaire, 12 items of school safety were evaluated. Safety status of the schools, overall and in each item, was calculated from the total score of 100. The relationship between school characteristics and its safety status was also evaluated using the SPSS software and the following statistical tests: Spearman's correlation, independent sample t-test, one-way Analysis of Variance (ANOVA) with Tukey's post-hoc test. Statistical significance was set at $\mathrm{P}<0.05$.

Results: The mean of the overall school safety was $63.72 \pm 8.97$. Among safety items of the schools, the mean of the fire control item had the least score (34.03 \pm 14.16$)$. Overall school safety was significantly better in larger schools, in schools with more land area (P $=0.009)$, more yard surface area $(\mathrm{P}=0.044)$, higher number of classes $(\mathrm{P}=0.003)$, and higher number of staffs $(\mathrm{P}=0.006)$. However, there were no significant differences between overall safety scores of elementary, middle, and high schools $(\mathrm{P}=0.098)$, as well as between governmental and private schools $(\mathrm{P}=0.954)$.

Conclusions: Safety status of Shiraz schools, especially in fire control item, was not desirable. Therefore, interventions for improving the status are necessary. Safer heating system should be used in schools and all schools should have appropriate fire extinguishers. These interventions are necessary for all school grades, including elementary, middle and high schools, and for both governmental and private schools.
\end{abstract}

Keywords: Schools, Safety, Related Factor, Shiraz

\section{Background}

Respecting safety issues in educational institutions is one of the most important elements, which effect both physical and mental aspects of students' natural growth. Because our country has a young population, a high percentage of our population is students. Therefore, paying attention to students' health can significantly reduce the incidence of physical and mental disorders in the country (1). Injury is a major problem in public health that strikes mostly children and teenagers, and requires serious consideration (2). The World Health Organization (WHO) has reported that accidents are one of the main causes of worldwide child mortality; it led to 950000 deaths in under 18-year-old youth during year 2004 (3). The safety of the environment, specially the safety of schools' environment is an important issue in prevention of accidents. Children spend most of their time at school. Therefore, accidents, injuries and even death will occur, if the school environ- ment is not safe (1). Studies have shown that the prevalence of accidents within schools is more than other environments (4). Furthermore, it has been shown that most of the events leading to bone fractures at schools are preventable through changes in the safety status of the school environment (5). School safety is also associated with other important issues. For example, a study conducted on data recruited from 31 provinces of China showed a positive relationship between school safety and students' selfesteem (6). Furthermore, a Mexican study showed that parental perception of school safety influenced their children's physical activity (7). In addition, a study in Québec reported that an increase in the students' feelings of safety at school was associated with better student classroom engagement (8).

So far, several studies have investigated schools regarding different aspects related to children's health. Most of the schools in Birjand (9) and about 30\% of primary schools of Yasouj (10), had unfavorable environmental 
health. Less than half of the water drinking areas and toilets in Yasuj schools had sanitary conditions (10). Only $76.6 \%$ of the primary schools of Isfahan complied with environmental health standards and only $80.5 \%$ of the classrooms had the desired conditions (11). Only $40 \%$ of the primary schools in Tehran had appropriate entry and exit points (1). Regarding environmental health, safety and agronomy, most of the primary schools in Markazi province were not in a suitable condition. Furthermore, more than half of the schools of the latter province were either in the vicinity of an unsafe situation such as highways, construction, welding or lathe workshop, or there were open channels and hollows on the entry of the schools (12). Only 70\% of the classrooms of Pakdasht schools had enough space. Only in half of the schools of the latter city, windows were at a standard position (13). Only in half of the schools of Tehran, half of the standards of sports equipment were respected (14). In Kashan, 50\% of futsal goals, $44 \%$ of volleyball net bars, and $20 \%$ of basketball bases were in unfavorable and unsafe conditions (15). In Parsabad Moghan, $65 \%$ of schools did not have a room for health services. There was a health teacher only in $58 \%$ of the schools of this city. Moreover, $13 \%$ of upstairs windows of the schools did not have any guards. Also, in 13\% of the schools, the classroom space per student was not adequate (16). In a study conducted in Tehran, Golestan, Khorasan Razavi, Boushehr and Ardebil, less than 50\% of the schools had clean and stainable walls and classrooms with adequate space. Only $21 \%$ of the schools had appropriate desks and chairs. Furthermore, less than 10\% of the upstairs windows had guards (17). In Riyadh, only one-fifth and one-fourth of the primary schools were ideally situated and had proper buildings, respectively. In addition, only $25 \%$ of the classrooms were suitably illuminated and had adequate window and floor area. Furthermore, drinking fountains per pupil were inadequate (18).

All these studies have implied the poor status of school safety. However, to the best of our knowledge, there has been no research that has comprehensively reviewed the school safety situation in Shiraz. It should be noted that because of the unsafe condition of schools, three huge fire accidents have occurred in the recent years in Iran. The accidents led to the burning of 51 students; 15 killed and 11 disabled (19-21). These and other similar accidents imply the necessity of strategies to improve school safety. To implement an interventional program in this regard, comprehensive information about the current status is necessary.

Shiraz is one of the largest cities of Iran, with a population of 1460665 (22), and 250832 students during year 2011 (23). The prevalence of accidents among middleschool students in 2005 was estimated as 1.2\% (24). Studies also showed that 107 of every hundred thousand students that were studying in Fars province schools had been involved in accidents at school (4). However, to the best of our knowledge, no study has investigated the safety situation of schools in this city.

\section{Objectives}

The present study was designed to evaluate the safety status of the schools of Shiraz and its related factors. We hope the results of the study could be used for planning strategies to improve the current situation.

\section{Methods}

This cross-sectional study was conducted on elementary, middle and high schools of Shiraz, the central city of Fars province, during April and May 2013. In this study, 310 schools were randomly selected from 1028 Shiraz schools. The sample size was calculated as 280 schools based on the estimation of 50\% safety of schools in different items, 95\% confidence interval and 0.05 precision, after correction for the finite population. However, considering $10 \%$ probability of non-cooperation, we selected 310 schools. To select the schools, the Shiraz schools' information was obtained from the Shiraz department of education and a multi-stage random sampling was conducted. The first stage of the sampling was stratified random sampling. At this stage, each of the four areas of Shiraz department of education were considered as a stratum and the schools were selected from each stratum based on the proportion of its schools. The second stage was also stratified random sampling. The schools of each area were divided to two stratum, girls' and boys' schools and the schools were selected from each stratum based on proportion of its schools. In order to select the schools, lottery was done among the schools of each stratum.

The data gathering tool was a researcher-made questionnaire about the safety of schools, which was designed based on the school health guideline, standardized by the Institute of Standards and Industrial Research of Iran (25). Content validity of the questionnaire was approved by the experts of safe community, affiliated by Shiraz University of Medical Sciences. Its reliability was also assessed using Cronbach's alpha $(\alpha=80 \%)$. The questionnaire consisted of 13 questions about demographic information of the schools and 95 questions about 12 items of school safety. The safety items were about the school environment (6 questions), classes (9 questions), school-yard (11 questions), corridors (7 questions), stairs (7 questions), first aids (4 questions), the items in the first aid box (16 questions), fire control (9 questions), electricity (7 questions), heating 
and cooling system (13 questions), chemicals (2 questions), and the performance of the school security (4 questions). It should be noted that the item of school security performance was designed only for elementary schools while other items were related to all three educational levels, elementary, middle and high schools. There were three options, "yes", "no", and "not relevant", for each question on school safety.

Each question of the questionnaire that was answered "no" was scored zero. Also the questions that were answered "yes" and "not relevant" were scored one. The score of each item of school safety was calculated as the sum of the scores of the questions of that item. To compare different items, the scores of each item and also the overall school safety were calculated based on the total score of 100.

After obtaining permission from the department of education, two health teachers were trained about how they should complete the questionnaire. They were referred to the selected schools. Giving explanations about the objectives of the research and obtaining the consent of the school authorities, they completed the questionnaires by visiting different areas of the schools and interviewing the schools authorities.

The collected data was entered in the SPSS statistical software version 16 . The overall school safety and the safety of schools in each item were reported as mean and standard deviation. The relationship between the overall school safety and characteristics of the schools was reported using Spearman's correlation test, independent sample T test, one-way analysis of variance (ANOVA) test with Tukey's post-hoc test. For all analyses, statistical significance was set at $\mathrm{P}<0.05$.

\section{Results}

The authorities of 301 of the 310 selected schools consented to be enrolled in the study (response rate $=97 \%$ ). Overall, 221 (73.4\%) of the participated schools were governmental and 142 (47.2\%) were elementary schools. The mean number of students in the schools was $271 \pm 157$ and the mean number of school staff was $27 \pm 14$ (Table 1).

The mean score of the overall school safety was 63.72 \pm 8.97 . However, there were many of differences among mean scores of 12 items of school safety. The least and the highest scores were in the fire control item (mean \pm SD: $34.03 \pm 14.16$ ) and stairs safety item (mean \pm SD: $85.90 \pm$ 13.45), respectively (Table 2).

The overall school safety was not significantly related to the time since the establishment of the school $(\mathrm{rho}=$ $0.0 .091, \mathrm{P}=0.131$ ), the floor area of the school ( $\mathrm{rho}=0.206$, $\mathrm{P}=0.001$ ), the average area of each floor of the school (rho
Table 1. Descriptive Characteristics of the Studied Schools-Shiraz, $2013(\mathrm{n}=301)$

\begin{tabular}{|c|c|}
\hline Schools Characteristics & Values \\
\hline $\begin{array}{l}\text { Time since the school establishment (years), median } \\
\text { (min-max) }\end{array}$ & $19.5(1-85)$ \\
\hline Total land area of the school $(\mathrm{m})$, mean \pm SD & $2550 \pm 1743$ \\
\hline The floor area of the school $(\mathrm{m})$, mean $\pm S D$ & $1302 \pm 1052$ \\
\hline The area of the school yard $(\mathrm{m})$, mean $\pm S D$ & $1527 \pm 1298$ \\
\hline $\begin{array}{l}\text { The average area of each floor of the school }(\mathrm{m}) \text {, mean } \pm \\
\text { SD }\end{array}$ & $691 \pm 490$ \\
\hline The number of students at the school, mean \pm SD & $271 \pm 157$ \\
\hline The number of school staff, mean \pm SD & $27 \pm 14$ \\
\hline The number of school floors, median (min-max) & $2(1-6)$ \\
\hline The number of school classes, median (min-max) & $10(1-27)$ \\
\hline \multicolumn{2}{|l|}{ Educational grades, No. (\%) } \\
\hline Elementary School & $142(47.2)$ \\
\hline Middle School & $71(23.6)$ \\
\hline High school & $88(29.2)$ \\
\hline \multicolumn{2}{|l|}{ Type of school, No. (\%) } \\
\hline Governmental & $221(73.4)$ \\
\hline Private & $77(25.6)$ \\
\hline Unknown & $3(1.0)$ \\
\hline \multicolumn{2}{|l|}{ Type of ownership, No. (\%) } \\
\hline Governmental or private & $272(90.4)$ \\
\hline Leased & $8(2.7)$ \\
\hline Charitable or devotion & $9(3.0)$ \\
\hline Unknown & $12(4.0)$ \\
\hline
\end{tabular}

Abbreviations: M, meter; n: number; SD, standard deviation.

$=0.178, \mathrm{P}=0.022)$ and the mean number of students at the schools ( $\mathrm{rho}=0.096, \mathrm{P}=0.099)$. However, the overall school safety increased by increasing total land area of the school ( $\mathrm{rho}=0.170, \mathrm{P}=0.005$ ), the area of the schoolyard (rho $=0.191, \mathrm{P}=0.004)$, and the number of the school staff (rho $=0.148, \mathrm{P}=0.011)$ and classes $(\mathrm{rho}=0.161, \mathrm{P}=0.005)$.

There was not a significant difference among the overall safety of the elementary, middle and high schools ( $\mathrm{P}$ $=0.098)$. However, there was a significant difference between the three educational grades regarding several items of the school safety including, first aids $(P=0.008)$, safety of chemicals $(\mathrm{P}=0.003)$, stairs safety $(\mathrm{P}=0.033)$, and the items in first aids box $(\mathrm{P}=0.006)$. The safety of the mentioned items in the elementary schools was significantly better than that of high schools (Table 3).

Also, there was no significant difference between the overall safety of governmental and private schools $(\mathrm{P}=$ 0.954). However, some items of school safety, heating and 
Table 2. The Safety Scores of the Studied Schools in Different Items $(\mathrm{n}=301)$

\begin{tabular}{|c|c|c|c|c|c|c|}
\hline \multicolumn{2}{|r|}{ School Safety Items } & \multicolumn{5}{|c|}{ School Safety Scores } \\
\hline $\mathbf{N}$ & Item & Mean & SD & Median & Minimum & Maximum \\
\hline 1 & School environment & 53.15 & 22.32 & 50.00 & 0 & 100 \\
\hline 2 & School yard & 65.59 & 9.16 & 63.63 & 45.45 & 100 \\
\hline 3 & Classes & 70.09 & 17.85 & 77.77 & 0 & 100 \\
\hline 4 & Corridors & 72.66 & 16.40 & 71.42 & 14.29 & 100 \\
\hline 5 & First aids & 65.94 & 16.17 & 75.00 & 0 & 100 \\
\hline 6 & Items in first aid box & 58.09 & 18.78 & 62.50 & 0 & 100 \\
\hline 7 & Fire control & 34.03 & 14.16 & 33.33 & 0 & 88.89 \\
\hline 8 & Stairs & 85.90 & 13.45 & 85.71 & 28.57 & 100 \\
\hline 9 & Electricity & 46.74 & 24.37 & 42.85 & 0 & 100 \\
\hline 10 & Heating and Cooling System & 65.60 & 22.17 & 69.23 & 7.69 & 100 \\
\hline 11 & Chemicals & 76.41 & 35.00 & 100 & 0 & 100 \\
\hline 12 & School security performance & 69.93 & 43.31 & 100 & 0 & 100 \\
\hline & Overall school safety & 63.72 & 8.97 & 63.74 & 37.24 & 82.66 \\
\hline
\end{tabular}

Abbreviations: n, number; SD, standard deviation.

Table 3. The Relationship Between Different Aspects of the School Safety and the School Grades ( $(n=301)^{\mathrm{a}}$

\begin{tabular}{|c|c|c|c|c|c|}
\hline \multicolumn{2}{|r|}{ School Safety Items } & \multicolumn{3}{|c|}{ Educational Grades } & \multirow[t]{2}{*}{ P Value } \\
\hline $\mathbf{N}$ & Item & Elementary School $($ Mean \pm SD) & Middle School $($ Mean \pm SD) & High School $($ Mean \pm SD $)$ & \\
\hline $\mathbf{1}$ & School environment & $52.46 \pm 22.18$ & $55.16 \pm 23.16$ & $52.65 \pm 22.01$ & 0.687 \\
\hline 2 & School yard & $65.36 \pm 9.62$ & $65.27 \pm 8.27$ & $66.32 \pm 9.16$ & 0.674 \\
\hline 3 & Classes & $69.71 \pm 16.95$ & $69.64 \pm 20.22$ & $71.08 \pm 17.39$ & 0.828 \\
\hline 4 & Corridors & $73.34 \pm 16.60$ & $72.63 \pm 16.68$ & $71.59 \pm 15.98$ & 0.736 \\
\hline 5 & Items in the first aid box & $59.99 \pm 16.71^{\mathrm{a}}$ & $60.91 \pm 17.44^{\mathrm{a}}$ & $52.77 \pm 21.85^{b}$ & 0.006 \\
\hline 6 & Fire control & $32.71 \pm 13.41$ & $33.95 \pm 13.52$ & $36.23 \pm 15.66$ & 0.185 \\
\hline 7 & Stairs & $87.42 \pm 13.12^{\mathrm{a}}$ & $86.72 \pm 12.15 \mathrm{a}^{\mathrm{a}, \mathrm{b}}$ & $82.79 \pm 14.55^{\mathrm{b}}$ & 0.033 \\
\hline 8 & Electricity & $47.48 \pm 22.73$ & $46.27 \pm 26.72$ & $47.94 \pm 25.02$ & 0.882 \\
\hline 9 & Heating and Cooling System & $65.65 \pm 22.82$ & $65.22 \pm 22.66$ & $65.82 \pm 20.92$ & 0.985 \\
\hline 10 & Chemicals & $83.45 \pm 26.44^{\mathrm{a}}$ & $72.53 \pm 40.34^{\mathrm{a}, \mathrm{b}}$ & $68.18 \pm 40.24^{\mathrm{b}}$ & 0.003 \\
\hline 11 & First aids & $68.66 \pm 12.43^{\mathrm{a}}$ & $65.49 \pm 16.56^{\mathrm{a}, \mathrm{b}}$ & $61.93 \pm 20.05^{\mathrm{b}}$ & 0.008 \\
\hline 12 & School security performance & $69.93 \pm 43.31$ & - & - & - \\
\hline & Total school safety & $62.93 \pm 8.33$ & $65.32 \pm 9.19$ & $63.71 \pm 9.68$ & 0.187 \\
\hline
\end{tabular}

${ }^{\mathrm{a}}$ Different letters show statistically significant differences.

cooling system $(\mathrm{P}=0.029)$ and the safety of classes $(\mathrm{P}=$ $0.013)$, were significantly better in private schools when compared with public schools (Table 4).

\section{Discussion}

The present study investigated the safety status of Shiraz schools and its related factors. Shiraz schools, on average, had about two-thirds of the studied standards of school safety. Among different items of school safety, the lowest score belonged to the fire control item. The 
Table 4. The Relationship Between Different Items of the School Safety and the School Type ( $n=301)$

\begin{tabular}{|c|c|c|c|c|}
\hline \multicolumn{2}{|r|}{ School Safety Items } & \multicolumn{2}{|c|}{ School Type } & \multirow[t]{2}{*}{ P Value } \\
\hline $\mathbf{N}$ & Item & Governmental (Mean \pm SD) & Private (Mean $\pm S D$ ) & \\
\hline $\mathbf{1}$ & School environment & $54.29 \pm 22.02$ & $49.13 \pm 22.92$ & 0.081 \\
\hline 2 & School yard & $65.32 \pm 8.95$ & $66.23 \pm 9.87$ & 0.455 \\
\hline 3 & Classes & $68.47 \pm 18.65$ & $74.31 \pm 14.67$ & 0.013 \\
\hline 4 & Corridors & $73.36 \pm 16.11$ & $70.68 \pm 17.32$ & 0.219 \\
\hline 5 & Items in the first aid kit & $59.33 \pm 18.51$ & $54.87 \pm 19.22$ & 0.072 \\
\hline 6 & Fire control & $33.78 \pm 12.77$ & $35.35 \pm 17.45$ & 0.402 \\
\hline 7 & Stairs & $86.36 \pm 13.53$ & $84.60 \pm 13.46$ & 0.326 \\
\hline 8 & Electricity & $46.80 \pm 24.63$ & $46.38 \pm 24.21$ & 0.898 \\
\hline 9 & Heating and Cooling System & $63.90 \pm 22.73$ & $70.32 \pm 20.07$ & 0.029 \\
\hline 10 & Chemicals & $76.47 \pm 35.84$ & $75.32 \pm 33.07$ & 0.806 \\
\hline 11 & First aids & $65.72 \pm 16.12$ & $66.55 \pm 16.52$ & 0.698 \\
\hline \multirow[t]{2}{*}{12} & School security performance & $44.05 \pm 45.29$ & $60.00 \pm 43.70$ & 0.591 \\
\hline & Total school safety & $63.14 \pm 9.10$ & $63.07 \pm 9.18$ & 0.954 \\
\hline
\end{tabular}

overall safety status of the schools was better in larger schools. However, there was no significant difference among the overall school safety of elementary, middle and high schools and between the governmental and private schools.

In our study, Shiraz schools on average had $63 \%$ of the standard criteria of school safety. Similarly, the environmental health and safety of the schools of Parsabad Moghan were not appropriate (16). Furthermore, the safety situation of most of Pakdasht schools was at a moderate level (13). The students make up a vast majority of our society. This vulnerable group is the future of the country. Therefore, it is essential that the authorities plan interventional programs to improve the situation as soon as possible. In this regard, private schools that have not been built based on building standards and environmental health regulations should not be permitted to continue their work. Also, to monitor the construction and renovation of governmental school buildings, laws should be established. department of modernization, development and equipping schools should investigate the defects of the school buildings and try to resolve them.

In our study, the lowest score for the school safety items belonged to the fire control item. Shiraz schools, on average, had $34 \%$ of the standard criteria for fire control. Similarly, $10 \%$ of the schools in Pakdasht did not have fire extinguisher with a valid date (13). In $10 \%$ of the elementary and middle schools of Zabol, fire extinguishers were not in a favorable condition (26). In the recent years, at least three major fire accidents have occurred in Iranian schools. The irreparable results of the accidents highlight the importance of attention to school safety, especially in the fire control item. Therefore, it is recommended to check the availability, fullness, and expiration date of fire extinguishers of the schools at the beginning of each academic year. To reduce the damages of fire accidents in schools as much as possible, it is also essential for theoretical and practical training sessions on how to use a fire extinguisher to be held for school staff.

This study showed that Shiraz schools had about twothirds of the safety standards of heating and cooling systems. Similarly, only half of the schools in Zabol had an appropriate heating and cooling system (26). Lack of attention to the heating and cooling system causes irreparable damages. During December 2012, 29 students were burned in Piranshahr because of the heating equipment malfunction; two died and three became handicapped because of severe injuries (19). Also, 13 students during January 2004 in Chaharmahal-o-Bakhtiari (20) and eight students during January 2006 in Doroodzan village of Fars province were burned because of the use of unsafe heaters (21). School authorities should ensure that the air conditioners and heaters of schools are intact. It is better if central air-conditioning systems are used in schools. Furthermore, the valves of water coolers, which are installed behind the class windows, should be covered by nets. The department of education in collaboration with other relevant departments such as gas and electricity organization should try to resolve the possible problems of heating and cooling equipment at schools. 
In our study, on average, about half of (58\%) the essential items existed in the first aid boxes of the schools. Similarly, the first aid equipment of schools was weak in a study in Ahwaz (27). However, a study in Pakdasht showed that there was a first aid box in all studied schools (13). Furthermore, teachers in Ahwaz did not have adequate knowledge and skills regarding use of the first aid box (27). The facilities and equipment of the first aid box has a critical role in reducing injuries when an accident occurs at schools. Therefore, the existence of all the necessary items in the first aid boxes of schools is important. The department of education should evaluate the first aid boxes of schools and complete the shortages.

In this research, the highest score of school safety belonged to the item of stair safety. Similarly, in a research conducted in Tehran, the safety of the stairs at elementary schools was desirable (1). Nevertheless, in a study in Zabol, only half of the elementary and middle schools, had appropriate stairs (26). To prevent accidents, the school stairs should obey all the rules related to the construction buildings such as the location and direction of stairs, the width of the staircase, the height of steps, the number of steps in one direction, and the situation of stair rails. providing enough light, especially at the beginning and end of stairs, is necessary. To prevent students slipping on rainy and snowy days, small rugs should be put in front of stairs. To prevent students falling down, rails should be present in all stairways.

In our study, the overall safety of schools among the elementary, middle and high schools was not significantly different. Therefore, authorities should set up interventional programs to improve school safety in all schools. Furthermore, there was no significant difference between the overall safety of governmental and private schools. However, in southeastern Nigeria, the mean evaluation scale of school health program in private schools was significantly higher than that of public schools (28). Furthermore, in Wales, accident report rates from schools in deprived wards were three times higher than those from schools in more affluent wards (29). In contrast, in Qazvin, governmental schools had a better condition than private schools in some safety items (30). It seems that school safety in both public and governmental schools is not favorable. Therefore, it is essential to set up interventional programs to improve the situation in both school types.

To improve school safety, it is recommended to revise the rules of the construction of school buildings. Only schools with buildings that comply with the standards of environmental health should be permitted to operate. Moreover, schools should frequently be observed to ensure that the used equipment, specially their heating systems, is standard. Furthermore, to prevent accidents, promotion of safety culture in schools is necessary. Bena et al. evaluated the effectiveness of the interventions whose objective was the promotion. They found a positive short-term effect for the programs on students' injuries (31). In addition, to reduce injuries after accidents, health teachers, students and school authorities should be trained regarding the principles of first aids. A study, which evaluated the emergency preparedness of the school transportation staff in the United States, showed that $89 \%$ of the staff had previously been trained in first aid. Furthermore, 52\% and 28\% of them were qualified in cardiopulmonary resuscitation and basic life support, respectively (32). Training the skills to the staff of our schools can improve the catastrophic results of our students' accidents.

Despite great efforts of researchers to optimally perform the current study, there were limitations in the course of the research. Firstly, as this study was cross sectional, evaluating the factors affecting school safety was not adequately valid. Therefore, to evaluate the risk factors, prospective longitudinal studies should be designed. Furthermore, other limitations of a cross sectional study may be involved in this study. Secondly, since there was no standard questionnaire to assess school safety, the researchers used a researcher-made questionnaire. Therefore, comparing the results of this study with the results of other studies was difficult. Thirdly, despite the researchers' efforts to gain the cooperation of the school authorities, some of them were not willing to cooperate. However, because the percentage of authorities, who did not cooperate was very low (3\%), we hope that their lack of cooperation has not significantly effected the validity of the results. Finally, although the researchers mostly completed the questionnaires after visiting the schools, completing some parts of the questionnaires was done by interviewing the school authorities, who might respond with a lack of honestly. To obtain correct answers, we emphasized on the confidentiality of the responses so we hope the questions were answered honestly.

\subsection{Conclusion}

The school safety in Shiraz, especially in the fire control item, was not satisfactory. To improve the current status, all three educational grades, elementary, middle, and high schools, as well as both public and private schools need interventional programs. The occurrence of multiple accidents in the recent years that have led to numerous cases of death and disability in children, highlights the importance of interventional programs. The most important measures in this regard is improving the condition of heating systems of the schools and equipping all schools with intact fire extinguishers with a valid date. 


\section{Acknowledgments}

The authors would like to thank the vice chancellor for research affairs of Shiraz University of Medical Sciences for financial support of this research. Also, we thank Shiraz department of education for permission and cooperation in the data collection and Ms. Effat Hadizadeh, the expert of disease control at Shiraz University of Medical Sciences, for her assistance in completing the questionnaires.

\section{Footnotes}

Authors' Contribution: Soheila Shaghaghian, analysis and interpretation of data, drafting of the manuscript, and critical revision of the manuscript for important intellectual content; Belgheys Malekzadeh, study concept and design, acquisition of data, and drafting of the manuscript; Mehrab Sayadi, statistical analysis.

Funding/Support: This study was supported by grant\#6127-9 from the vice chancellor for research affairs of Shiraz University of Medical Sciences.

\section{References}

1. Johari Z, Ramezankhani A, Zarpak B. Evaluation of safety status in Tehran elementary schools. J Shahid Sadoughi Univ Med Sci. 2001;8(4):30-4.

2. Martinov-Cvejin M, Jakovljevic D, Nalcic B, Grujic V, Ac-Nikolic E. [Knowledge, attitude and practice in school children regarding traffic accident injuries]. Med Pregl. 1993;46(9-10):349-52. [PubMed: 7997212].

3. Peden M, Oyegbite K, Ozanne-Smith J, Hyder AA, Branche C, Rahman A, et al, editors. ; 2008. World Report on Child Injury Prevention.

4. Malekzade B, Alidoosti K, Darvishi M, Sayyadi M. Frequency and causes of accidents in elementary school students in Fars Province.. Journal of Nursing and Midwifery School. 2012;11:59-64.

5. Lyons RA, Delahunty AM, Kraus D, Heaven M, McCabe M, Allen H, et al. Children's fractures: a population based study. Inj Prev. 1999;5(2):12932. [PubMed: 10385833].

6. Zhang X, Xuan X, Chen F, Zhang C, Luo Y, Wang Y. The Relationship Among School Safety, School Liking, and Students' Self-Esteem: Based on a Multilevel Mediation Model.J Sch Health. 2016;86(3):164-72. doi: 10.1111/josh.12364. [PubMed: 26830502].

7. Hutchens A, Soltero EG, Barquera S, Levesque L, Jauregui E, Lopez YJ, et al. Influence of parental perception of school safety and gender on children's physical activity in Mexico: A cross sectional study. Salud Publica Mex. 2016;58(1):7-15. [PubMed: 26879502].

8. Cote-Lussier C, Fitzpatrick C. Feelings of Safety at School, Socioemotional Functioning, and Classroom Engagement. J Adolesc Health. 2016;58(5):543-50. doi: 10.1016/j.jadohealth.2016.01.003. [PubMed: 26976149].

9. Shahriari T, Moodi M, Hajiani M, Shahriari Z. Study of hygienic status of schools in Birjand during year 2007-2008.J Birjand Univ Med Sci. 2009;16(2):68-75.

10. Raegan SA, Shahraki GH, Fararooei M. Survey of environmental health in yasuj primary schools. J Yasuj Univ Med Sci. 2001;6(21):55-61.

11. Sharifirad G, Baghianimoghadam MH, Pirzadeh A, Oruji MA, Ehramoush MH, Baghianimoghadam B. Comparison of environmental health status in primary schools in different districts of Isfahan city in 2008-2009. J Prev Med Hyg. 2011;52(2):83-8. [PubMed: 21842710].
12. Zare R, Jalalvandi M. Ergonomic, Safety and Environmental Health Status of Primary Schools in Markazi Province. Iran in 2003-2004. J Kerman Univ Med Sci. 2007;14(1):61-9.

13. Kermani M, Farzadkia M, Yousefi Z, Ghandali R. Investigating the environmental health and safety status among primary schools.J Mazand Univ Med Sci. 2012;22(95):85-9.

14. Farsi A, Zamani Sani H, Fathi Rezayi Z. Safety standards of sport equipment and area in Tehran Schools and recommendation for solving potential problems (Persian). Quarterly Journal of Educational Innovations. 2012;11(43):61-80.

15. Sayyah M, Dehkhoda M, Arab Ameri A. bidgholi M. Evaluation of safety status of sport places in Kashan in 2005. Presented in first national congress of city and sport in 2006 (Persian). 2005

16. Dargahi A, Jangjoo S, Dargahi A, Amirian T. Environmental health and safety of schools in Pars Abad Moghan during 2012-2013 (Persian). Presented in 16th national congress of Iran Environmental Health.

17. Aghili MMM, Jafari AJ, Zia-oddini H. The Assessment of Establishment and Maintenance of the Health Management System in Schools and Grading for Awarding Stars (HSE-ms). J Isfahan Med School. 2010;28(107).

18. Sinha NP, Shabrawy ME, Nasser AA, Hossain A. Environmental health in primary schools in a developing country.J Hyg Epidemiol Microbiol Immunol. 1991;35(2):123-8. [PubMed: 1940327].

19. Piranshahr fire frightener report from fire accident in Shin Abad School: cause of accident had been oil heaters Available from: http: //www.khabaronline.ir/detail/262166.

20. Fire in Safilan School Available from: https://fa.wikipedia.org/wiki.

21. A school burnt in fire Available from: http://www.kffr.com/ musicvideo.php?vid=32a148bd7.

22. What is the population of each city of Iran? Available from: http:// www.bazarkhabar.ir/News.aspx?ID=48243.

23. Statistics from School Health Unit of Health Vice Chancellor of Shiraz University of Medical Sciences (Persian). 2013

24. Amirzade F, Tabatabayi $\mathrm{H}$. Incidence and causes of accidents in students of Shiraz middle schools. J Kerman Univ Med Sci. 2006;14(1):5560.

25. School hygiene standard commission, School hygiene first revision (Persian). 2003

26. Neshat AA, Dastoorani MJ, Ramazani AA, Changizi H, Jabbarzare M. Investigation of Environmental Health and safety situations in elementary and guide schools of Zabol, 2010. 2011

27. Hassani A, Hemmatinejad M, Noorbakhsh M, Mahdipoor A. Description and comparison of safety management in sport classes of Ahvaz middle schools. Journal of Sport Sciences. 2008;4(8):11-28..

28. Ezeonu CT, Anyansi MN. Environmental health assessment of primary schools in southeastern Nigeria: implication for a healthy school environment in developing countries. World health \& population. 2009;12(2):18-22.

29. Latif AH, Williams WR, Sibert J. Primary school accident reporting in one education authority. Arch Dis Child. 2002;86(2):91-4. [PubMed: 11827900].

30. Khalili A, Jahani Hashemi H, Jamaly H. A comparative study on safety and environmental health of public and private schools of Qazvin..J Qazvin univ of Med Sci. 2007;11(1):41-9.

31. Bena A, Farina E, Orengia M, Quarta D. Promotion of safety culture in Italian schools: effectiveness of interventions on student injuries. Eur J Public Health. 2016;26(4):587-92. doi: 10.1093/eurpub/ckw039. [PubMed: 27095793].

32. Olympia RP, Weber C, Brady J, Ho S. Emergency and Disaster Preparedness of School Transportation Staff and School Buses in the United States: Compliance With Recommendations for School Transportation Safety. Pediatr Emerg Care. 2016 doi: 10.1097/PEC.0000000000000704. [PubMed: 27176903]. 